\title{
Hydrogen sulfide in posthemorrhagic shock mesenteric lymph drainage alleviates kidney injury in rats
}

\author{
B. Han*, Z.G. Zhao*, L.M. Zhang, S.G. Li and C.Y. Niu \\ Institute of Microcirculation, Hebei North University, Hebei Zhangjiakou, China
}

\begin{abstract}
Posthemorrhagic shock mesenteric lymph (PHSML) is a key factor in multiple organ injury following hemorrhagic shock. We investigated the role of hydrogen sulfide $\left(\mathrm{H}_{2} \mathrm{~S}\right)$ in PHSML drainage in alleviating acute kidney injury (AKI) by administering D,L-propargylglycine (PPG) and sodium hydrosulfide hydrate (NaHS) to 12 specific pathogen-free male Wistar rats with PHSML drainage. A hemorrhagic shock model was established in 4 experimental groups: shock, shock + drainage, shock + drainage + PPG (45 mg/kg, $0.5 \mathrm{~h}$ prehemorrhage), and shock + drainage + NaHS (28 $\mu \mathrm{mol} / \mathrm{kg}, 0.5 \mathrm{~h}$ prehemorrhage). Fluid resuscitation was performed after $1 \mathrm{~h}$ of hypotension, and PHMSL was drained in the last three groups for $3 \mathrm{~h}$ after resuscitation. Renal function and histomorphology were assessed along with levels of $\mathrm{H}_{2} \mathrm{~S}$, cystathionine- $\gamma$-lyase (CSE), Tolllike receptor 4 (TLR4), interleukin (IL)-10, IL-12, and tumor necrosis factor (TNF)- $\alpha$ in renal tissue. Hemorrhagic shock induced AKI with increased urea and creatinine levels in plasma and higher $\mathrm{H}_{2} \mathrm{~S}, \mathrm{CSE}$, TLR4, IL-10, IL-12, and TNF- $\alpha$ levels in renal tissue. PHSML drainage significantly reduced urea, creatinine, $\mathrm{H}_{2} \mathrm{~S}$, CSE, and TNF- $\alpha$ but not TLR4, IL-10, or IL-12. PPG decreased creatinine, $\mathrm{H}_{2} \mathrm{~S}$, IL-10, and TNF- $\alpha$ levels, but this effect was reversed by NaHS administration. In conclusion, PHSML drainage alleviated AKI following hemorrhagic shock by preventing increases in $\mathrm{H}_{2} \mathrm{~S}$ and $\mathrm{H}_{2} \mathrm{~S}$-mediated inflammation.
\end{abstract}

Key words: Hemorrhagic shock; Mesenteric lymph; Drainage; Kidney injury; Hydrogen sulfide; Inflammation

\section{Introduction}

Acute kidney injury $(\mathrm{AKI})$ is a pathological process that commonly occurs in conditions such as hemorrhage, trauma, infection, or intoxication and contributes to the progression of internal milieu disorders, resulting in multiple organ failure (1-4). Recently, the relationship between lymph circulation and pathogenesis of serious diseases has received increasing attention, with evidence that under critical clinical conditions, the return of mesenteric lymph to the systemic circulation is a key factor in vital organ dysfunction and injury (5-7). The results obtained in our previous studies suggest that blocking the return of mesenteric lymph to the systemic circulation attenuates renal lesions induced by hemorrhage and lipopolysaccharide or severe hemorrhagic shock in a twohit animal model (8-10). However, the underlying mechanisms remain to be discovered.

Hydrogen sulfide $\left(\mathrm{H}_{2} \mathrm{~S}\right)$ is an endogenous gaseous signaling molecule involved in diverse biological processes such as inflammatory responses, energy metabolism, cell proliferation, apoptosis, and oxidative stress $(11,12)$. Recent studies indicate that $\mathrm{H}_{2} \mathrm{~S}$ is responsible for the inflammatory response and organ dysfunction following hemorrhagic shock (13). Pretreatment with D,L-propargylglycine (PPG), an inhibitor of cystathionine- $\gamma$-lyase (CSE), attenuates increases in plasma levels of tumor necrosis factor (TNF)- $\alpha$, interleukin (IL)-6, and urea and reduces $\mathrm{H}_{2} \mathrm{~S}$ concentration in the kidney following hemorrhagic shock (13). Francescato et al. (14) showed that treatment with PPG attenuates gentamicin-provoked effects such as macrophage infiltration in the renal cortex and interstitial lesions in renal tubules. These reports suggest that increased $\mathrm{H}_{2} \mathrm{~S}$ levels that mediate $\mathrm{AKI}$ are induced by renal ischemia or nephrotoxic drugs. However, an $\mathrm{H}_{2} \mathrm{~S}$-induced inflammatory response related to $\mathrm{AKI}$ caused by the return of posthemorrhagic shock mesenteric lymph (PHSML) has not yet been reported.

In this study, PPG and the $\mathrm{H}_{2} \mathrm{~S}$ donor sodium hydrosulfide hydrate (NaHS) were administered to rats subjected to hemorrhagic shock with PHSML drainage. The aim was to investigate the role of $\mathrm{H}_{2} \mathrm{~S}$ in PHSML drainage in the protection of renal function. Changes in the levels of Tolllike receptor 4 (TLR4), IL-10, IL-12, and TNF- $\alpha$ are

Correspondence: Chun-Yu Niu: <ncylxf@126.com>.

*These authors contributed equally to this study.

Received April 16, 2014. Accepted January 13, 2015. First published online April 28, 2015. 
described, and the mechanism of PHSML drainage in AKI is discussed.

\section{Material and Methods}

\section{Animals}

Thirty healthy, specific pathogen-free male Wistar rats weighing $220-260 \mathrm{~g}$ were purchased from the Chinese Academy of Medical Sciences Animal Breeding Center (Beijing, China). The rats were housed in a climatecontrolled facility with a 12-h light/dark cycle and free access to standard laboratory food and water for at least 1 week prior to the experimental procedures. The rats ware fasted and only allowed water for $12 \mathrm{~h}$ before the start of experimental procedures. Rats were randomly allocated to 5 groups: sham, shock, shock + drainage, shock + drainage + PPG, and shock + drainage + NaHS $(n=6 /$ group). All procedures involving animals were reviewed and approved by the Hebei North University Animal Care Committee and conformed to the guidelines of the National Institutes of Health. Maximum efforts were made to minimize animal suffering.

\section{Hemorrhagic shock model}

Rats were anesthetized with pentobarbital sodium (1\%, $50 \mathrm{mg} / \mathrm{kg}$ ), and those in the shock + drainage + PPG and shock + drainage + NaHS groups were given PPG (45 mg/mL, $45 \mathrm{mg} / \mathrm{kg}$; Sigma, USA) or NaHS (28 $\mu \mathrm{mol} / \mathrm{mL}, 28 \mu \mathrm{mol} / \mathrm{kg}$, Sigma) by intraperitoneal (ip) injection. Control animals (i.e., those in the sham, shock, and shock+drainage groups) were given ip injections of an equal volume of normal saline $(1 \mathrm{~mL} / \mathrm{kg})$. The PPG and NaHS doses were the same as those used in previous studies $(15,16)$. The right femoral vein was aseptically isolated, catheterized with polyethylene tubing containing heparin sodium $(500 \mathrm{U} / \mathrm{kg})$ for anticoagulation, and connected to an infusion pump (WZF250F2, Zhejing University Medical Instrument Company, China) for fluid resuscitation. The bilateral femoral arteries were also isolated. A minimally heparinized polyethylene catheter was introduced into the left femoral artery to allow continuous monitoring of mean arterial pressure (MAP) using a biological signal acquisition system (RM6240BD, Chengdu Instrument, China). Another catheter was inserted into the right femoral artery for blood letting. All rats then underwent abdominal surgery to separate the mesenteric lymph duct from the surrounding connective tissues. Rats in the shock, shock + drainage, shock + drainage + PPG, and shock + drainage + NaHS groups were allowed to stabilize for 30 minutes and were then hemorrhaged rapidly from the right femoral artery with an automatic withdrawal-infusion machine (NE-1000; New Era Pump Systems Inc., USA) so that the MAP dropped to $40 \mathrm{mmHg}$ within $10 \mathrm{~min}$. MAP was maintained at this level for 60 min through the withdrawal or reperfusion of lost blood as required. The collected blood plus an equal volume of Ringer's solution were then reperfused within $30 \mathrm{~min}$ through the right femoral vein.
After completion of resuscitation, the mesenteric lymph duct was cannulated, and PHSML was drained for up to $3 \mathrm{~h}$ in the shock +drainage, shock +drainage+PPG, and shock + drainage + NaHS groups. Rats in the sham group were anesthetized and cannulated as described above, but hemorrhage and resuscitation were not performed. At $3 \mathrm{~h}$ after resuscitation, a 3-mL blood sample was withdrawn from the abdominal aorta, and renal tissues were harvested for subsequent examination.

\section{Examination of renal function}

Plasma was collected by centrifugation at $850 \mathrm{~g}$ for $10 \mathrm{~min}$ and stored at $-75^{\circ}$ to $-80^{\circ} \mathrm{C}$ in a refrigerator (Thermo Electron, USA). Plasma urea and creatinine (Cre) levels were measured by an automatic biochemical analyzer (7600-110, Hitachi, Japan).

\section{Morphological observation of kidney}

Renal tissues were fixed in $4 \%$ paraformaldehyde after harvesting from a specified location in the rat kidneys. Following dehydration in a graded alcohol series and paraffin embedding, the renal tissues were sectioned at $5 \mu \mathrm{m}$ and stained with hematoxylin and eosin. Tissue morphology was examined by light microscopy (90i; Nikon, Japan) in 10 randomly chosen fields per sample and then photographed and analyzed using an image collection and analysis system (Eclipse, Nikon).

\section{Preparation of renal homogenate}

The isolated renal tissues were homogenized in 1:9 (w/v) physiological saline for $30 \mathrm{~s}$ using an FJ-200 tissue homogenizer (Shanghai Specimen and Model Factory, China). The homogenates were centrifuged at $850 \mathrm{~g}$ at $0-4^{\circ} \mathrm{C}$ for $10 \mathrm{~min}$ (Labofuge 400R; Thermo Fisher Scientific, USA), and the supernatants were kept frozen at $-75^{\circ}$ to $-80^{\circ} \mathrm{C}$ until they were used in subsequent assays.

\section{$\mathrm{H}_{2} \mathrm{~S}$ assays of renal homogenates}

A standard calibration curve was plotted using solutions containing different, known concentrations of NaHS. A linear regression equation $\left(y=1532.5 x+6.786, r^{2}=0.995\right)$ was derived to assay $\mathrm{H}_{2} \mathrm{~S}$ in the renal homogenates as previously described (13). Briefly, $0.1 \mathrm{~mL}$ renal homogenate was added to a test tube containing $0.5 \mathrm{~mL} 10 \mathrm{~g} / \mathrm{L}$ zinc acetate. After mixing, $0.5 \mathrm{~mL}$ p-phenylenediamine hydrochloride $(20 \mathrm{mmol} / \mathrm{L})$ and $0.5 \mathrm{~mL}$ ferric trichloride $(30 \mathrm{mmol} / \mathrm{L})$ were added to the reaction system, which was then incubated for $20 \mathrm{~min}$ at room temperature. After addition of I mL $10 \%$ trichloroacetic acid to precipitate albumin, the volume of the mixture was adjusted to $5 \mathrm{~mL}$ with distilled water and centrifuged for $5 \mathrm{~min}$ at $7400 \mathrm{~g}$. The absorbance of the resulting supernatant solutions was read at $670 \mathrm{~nm}$ using a spectrophotometer, and $\mathrm{H}_{2} \mathrm{~S}$ concentrations in the renal homogenates were calculated against the NaHS calibration curve. The proteins in the homogenates were quantified with the Coomassie brilliant blue colorimetric method (Jiancheng 
Biotechnology Research Institute, China). The results are reported as $\mu \mathrm{mol} \mathrm{H}_{2} \mathrm{~S}$ per mg protein.

\section{Assays of CSE and inflammatory factors in renal homogenates}

CSE, TLR4, IL-10, IL-12, and TNF- $\alpha$ levels in the renal homogenates were determined using a rat enzyme-linked immunoadsorbent assay (ELISA) kit and commercially available antibodies (R\&D Systems, USA). Results are reported as $\mu \mathrm{mol}$ per $\mathrm{mg}$ protein (CSE) and $\mathrm{ng} / \mathrm{mg}$ protein (TLR4, IL-10, IL-12, and TNF- $\alpha$ ).

\section{Statistical analysis}

Data are reported as means $\pm S D$, and the statistical analyses were performed using the SPSS software version 16.0 (SPSS Inc., USA). Differences of the means observed in the experimental groups were analyzed by one-way analysis of variance (ANOVA) followed by StudentNewman-Keuls tests. Differences between two group means were analyzed with independent sample $t$-tests. $\mathrm{P}<0.05$ was considered to be significant.

\section{Results}

\section{$\mathrm{H}_{2} \mathrm{~S}$ levels in renal tissue}

$\mathrm{H}_{2} \mathrm{~S}$ levels in renal tissue from the shock group were significantly higher than those in the sham group $(\mathrm{P}<0.01$, Figure 1). $\mathrm{H}_{2} \mathrm{~S}$ levels in the shock + drainage group were significantly lower than those in the shock group $(\mathrm{P}<0.05)$. PPG administration significantly decreased $\mathrm{H}_{2} \mathrm{~S}$ levels $(P<0.05)$, which were significantly lower than those observed in the shock group $(\mathrm{P}<0.01)$. NaHS administration significantly increased $\mathrm{H}_{2} \mathrm{~S}$ to levels similar to those in the shock group and significantly higher than those observed in the sham and shock + drainage groups $(\mathrm{P}<0.01)$.

\section{CSE levels in renal tissue}

As shown in Figure 2, CSE levels in renal tissue from the shock group were significantly higher than those in tissues

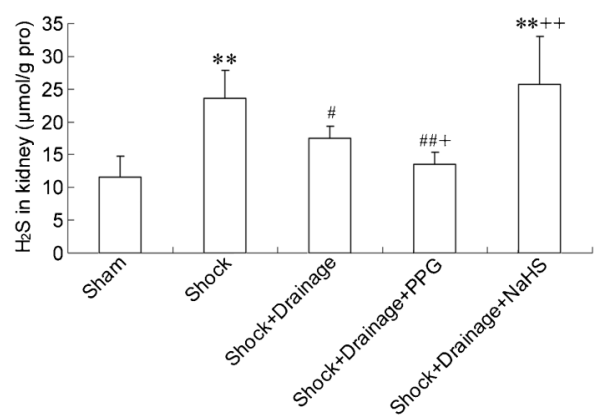

Figure 1. Changes in hydrogen sulfide $\left(\mathrm{H}_{2} \mathrm{~S}\right)$ levels in rat kidneys. Data are reported as means $\pm S D(\mu \mathrm{mol} / g$ protein, $n=6)$. PPG: $D, L-$ propargylglycine; NaHS: sodium hydrosulfide hydrate. ${ }^{* *} \mathrm{P}<0.01$ vs the sham group; ${ }^{\#} \mathrm{P}<0.05$, ${ }^{\#} \mathrm{P}<0.01$ vs the shock group; ${ }^{+} \mathrm{P}<0.05$, ${ }^{++} \mathrm{P}<0.01$ vs the shock + drainage group (one-way ANOVA).

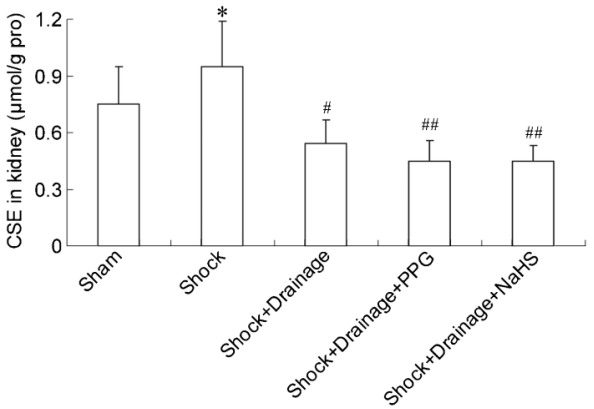

Figure 2. Changes in cystathionine- $\gamma$-lyase (CSE) levels in rat kidneys. Data are reported as means $\pm S D(\mu \mathrm{mol} / \mathrm{g}$ protein, $n=6)$. PPG: $D, L-$ propargylglycine; NaHS: sodium hydrosulfide hydrate. ${ }^{*} \mathrm{P}<0.05$ vs the sham group; ${ }^{\#} \mathrm{P}<0.05$, ${ }^{\# \#} \mathrm{P}<0.01$ vs the shock group (one-way ANOVA).

from the sham group $(P<0.05)$. CSE levels in tissues from the shock + drainage, shock + drainage + PPG, and shock + drainage $+\mathrm{NaHS}$ groups were significantly lower than that of the shock group $(\mathrm{P}<0.05, \mathrm{P}<0.01)$. The differences in CSE levels observed among the three experimental groups were not significant $(P>0.05)$.

\section{Renal function indices}

Figure 3 shows that hemorrhagic shock induced significant increases in plasma urea $(P<0.05)$ and $C r e$ $(P<0.01)$ levels and that $P H S M L$ drainage decreased urea and $C$ re levels $(P<0.05)$. PPG administration enhanced the effect of PHSML drainage on Cre $(P<0.05)$, whereas NaHS administration reversed the effect of PHSML drainage on urea $(P<0.05)$ and Cre $(P<0.01)$ levels.

\section{Renal morphology}

The architecture of glomeruli and renal tubules of rats in the sham group appeared normal (Figure 4A and B). Protein casts and erythrocytes were occasionally found in renal tubule lumens of rats in the shock group along with tubular epithelial cells with necrosis, karyopyknosis, and acidophilic degeneration (Figure $4 \mathrm{C}$ and $\mathrm{D}$ ). In the shock + drainage group, the glomeruli and tubules showed nearly normal architecture with normally arranged tubular epithelial cells containing integral nuclei with clear and complete membranes (Figure 4E and F). In the shock + drainage + PPG group, the glomeruli and tubules had nearly normal architecture with a few mildly edemic tubular epithelial cells (Figure $4 G$ and $H$ ). Finally, in the shock + drainage + NaHS group, the injury to tubular epithelial cells was significantly greater than that seen in the shock + drainage group. Acidophilic degeneration and edema were also noted in the tubular epithelial cells in some regions of tissue (Figure $4 \mathrm{I}$ and $\mathrm{J}$ ).

\section{TLR4 levels in renal tissue}

TLR4 levels in renal homogenates of the shock and shock+drainage groups were significantly higher than 

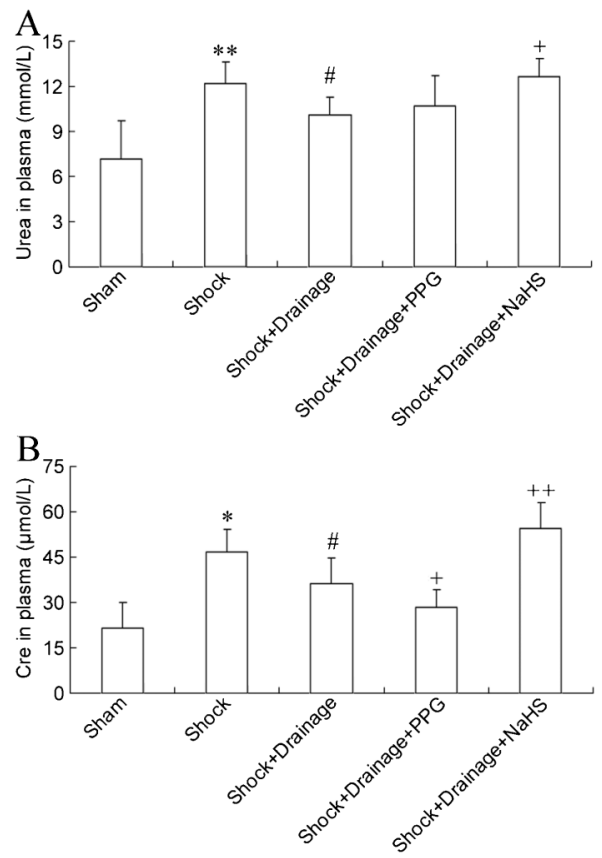

Figure 3. Changes in biochemical indices of renal function in rats. $A$, Urea in plasma; $B$, Creatinine (Cre) in plasma. Data are

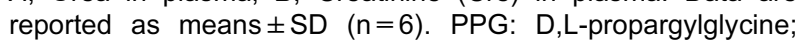
NaHS: sodium hydrosulfide hydrate. ${ }^{*} \mathrm{P}<0.05$, ${ }^{* *} \mathrm{P}<0.01$ vs the sham group; ${ }^{*} \mathrm{P}<0.05$ vs the shock group; ${ }^{+} \mathrm{P}<0.05,{ }^{++} \mathrm{P}<0.01$ $v s$ the shock + drainage group (one-way ANOVA).

levels in the sham group $(P<0.05)$. TLR4 levels in renal homogenates of the shock + drainage + PPG group showed a decreasing trend, but no statistical difference was found compared with the shock group $(P>0.05$, Figure 5). However, NaHS administration significantly increased TLR4 levels compared with those in the sham, shock, and shock +drainage groups $(\mathrm{P}<0.01)$.

\section{IL-10 and IL-12 levels in renal tissue}

IL-10 and IL-12 levels in renal homogenates from the shock and shock +drainage groups were significantly higher than those in the sham group $(P<0.05$, Figure 6$)$. PPG administration significantly decreased IL-10 levels $(P<0.05)$, but the decrease in IL-12 levels was not significant $(P>0.05)$. NaHS administration significantly enhanced IL-10 $(P<0.01)$ and IL-12 $(P<0.05)$ levels compared to the shock + drainage group, as well as with significant differences compared to the sham and shock groups $(\mathrm{P}<0.05, \mathrm{P}<0.01)$.

\section{TNF- $\alpha$ levels in renal tissue}

TNF- $\alpha$ levels in renal homogenates from the shock and shock +drainage groups were significantly higher than those in the sham group $(P<0.01)$, and the index in the shock+drainage group was lower than that in the

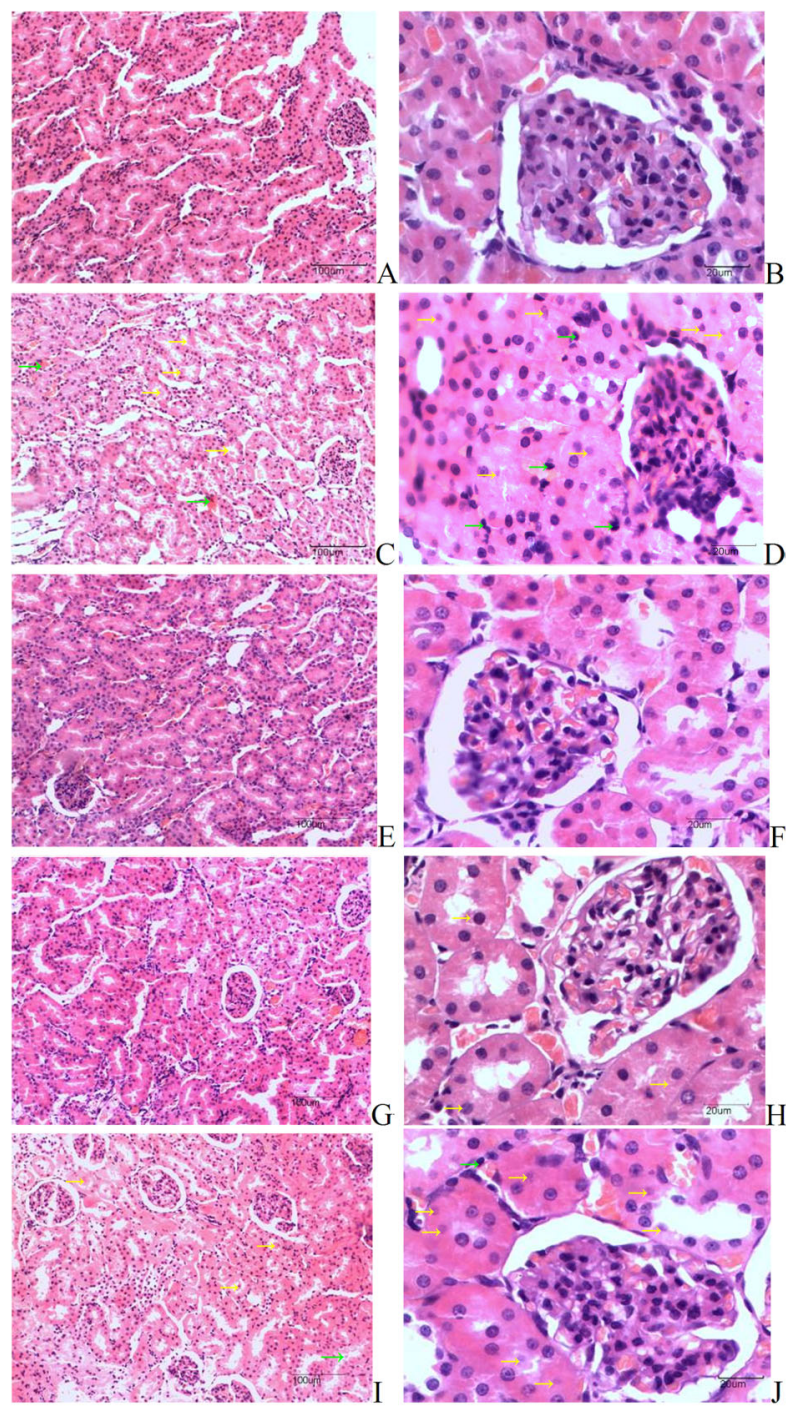

Figure 4. Changes in renal pathomorphology in rats (hematoxylin and eosin staining). $A, B$, sham group; $C, D$, shock group; $E, F$, shock + drainage group; $G, H$, shock + drainage + PPG group; $I, J$, shock + drainage + NaHS group. PPG: D,L-propargylglycine; NaHS: sodium hydrosulfide hydrate. Normal structure of renal glomeruli and tubules in the sham group is shown in $A$ and $B$; protein casts (yellow arrows) and erythrocytes (green arrows) were found in renal tubule lumens of rats in the shock and shock + drainage + NaHS groups, as shown in $C$ and $l$; tubular epithelial cells with necrosis (yellow arrows) and karyopyknosis (green arrows) were observed in the shock and shock + drainage + NaHS groups, as shown in $D$ and $J$; nearly normal architecture of glomeruli and tubules in the shock + drainage and shock + drainage + PPG groups is shown in $E, F, G$, and $H$, plus mild edema of tubular epithelial cells (yellow arrows) in $H$.

shock group $(P<0.05$, Figure 7). PPG administration significantly decreased TNF- $\alpha$ levels, with significant differences in the levels measured in the shock and shock + drainage 


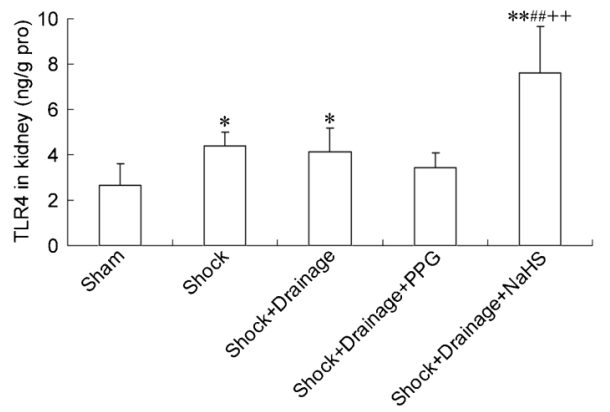

Figure 5. Changes in Toll-like receptor 4 (TLR4) levels in the renal homogenates of rats. Data are reported as means $\pm S D(\mathrm{ng} / \mathrm{g}$ protein, $n=6$ ). PPG: $D$,L-propargylglycine; NaHS: sodium hydrosulfide hydrate. ${ }^{*} \mathrm{P}<0.05,{ }^{*} \mathrm{P}<0.01$ vs the sham group; ${ }^{\# \#} \mathrm{P}<0.01$ vs the shock group; ${ }^{++} \mathrm{P}<0.01$ vs the shock + drainage group (oneway ANOVA).

groups $(\mathrm{P}<0.05$ and $\mathrm{P}<0.01$, respectively). NaHS administration significantly increased TNF- $\alpha$ levels in renal homogenates $(P<0.01)$.

\section{Discussion}

In the present study, we assayed $\mathrm{H}_{2} \mathrm{~S}$ levels in renal tissues to investigate the role of $\mathrm{H}_{2} \mathrm{~S}$ in PHSML drainage
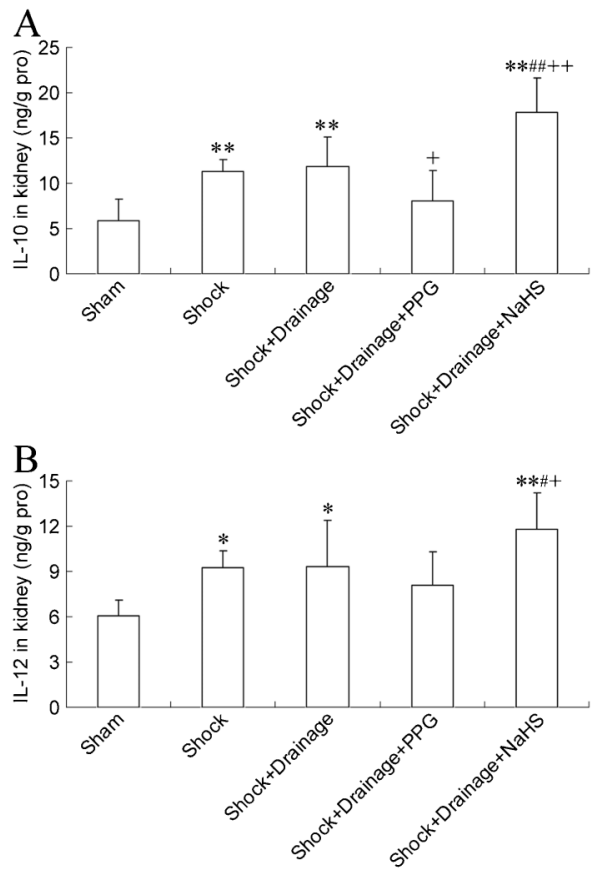

Figure 6. Changes in interleukin (IL)-10 $(A)$ and IL-12 (B) levels in the renal homogenates of rats. Data are reported as means $\pm S D$ (ng/g protein, $\mathrm{n}=6$ ). PPG: D,L-propargylglycine; NaHS: sodium hydrosulfide hydrate. ${ }^{*} \mathrm{P}<0.05$, ${ }^{* *} \mathrm{P}<0.01$ vs the sham group; ${ }^{\#} \mathrm{P}<0.05,{ }^{\# \#} \mathrm{P}<0.01$ vs the shock group; ${ }^{+} \mathrm{P}<0.05,{ }^{++} \mathrm{P}<0.01$ $v s$ the shock + drainage group (one-way ANOVA).

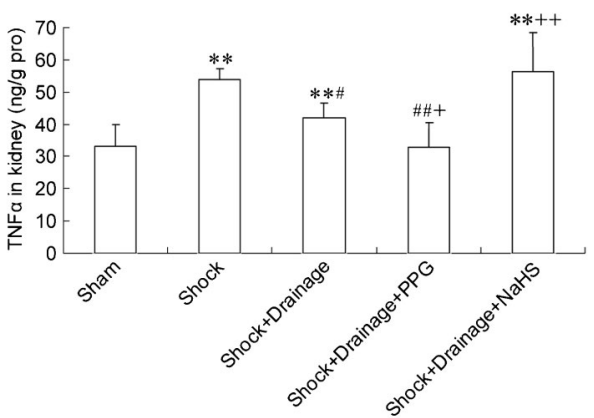

Figure 7. Changes in tumor necrosis factor (TNF)- $\alpha$ levels in the renal homogenates of rats. Data are reported as means $\pm S D(\mathrm{ng} / \mathrm{g}$ protein, $n=6$ ). PPG: $D, L-$ propargylglycine; NaHS: sodium hydrosulfide hydrate. ${ }^{* *} \mathrm{P}<0.01$ vs the sham group; ${ }^{\#} \mathrm{P}<0.05$, ${ }^{\# \#} \mathrm{P}<0.01$ vs the shock group; ${ }^{+} \mathrm{P}<0.05,{ }^{++} \mathrm{P}<0.01$ vs the shock + drainage group (one-way ANOVA).

responsible for alleviation of $\mathrm{AKI}$ in hemorrhagic-shocked rats. We found that the mean $\mathrm{H}_{2} \mathrm{~S}$ level was significantly increased in the shock group compared with the sham group. $\mathrm{H}_{2} \mathrm{~S}$ level was decreased by PHSML drainage and further reduced by PPG administration, but this effect was reversed by NaHS administration. Further investigation revealed that CSE levels were significantly increased in renal tissues from the shock group. Thus, PHSML drainage and PPG decreased CSE levels in renal tissues from the shock group, but NaHS had no significant effect on CSE levels, indicating that the decrease in $\mathrm{H}_{2} \mathrm{~S}$ was achieved by inhibition of CSE activity by PHSML drainage. NaHS, under the influence of CSE, directly generates $\mathrm{H}_{2} \mathrm{~S}$, which indicates that exogenous NaHS had no effect on CSE activity.

In addition to the effect of PHSML drainage on AKI resulting from inhibition of CSE activity and decreased $\mathrm{H}_{2} \mathrm{~S}$ levels, we found that plasma urea and Cre, which are biochemical indicators of renal function, significantly increased in the shock group and decreased after PHSML drainage. PPG enhanced the role of PHSML drainage, but $\mathrm{NaHS}$ had the opposite effect, indicating that $\mathrm{NaHS}$ reversed the impact of PHSML drainage, which is consistent with the observed differences in renal tissue morphology. Furthermore, $\mathrm{H}_{2} \mathrm{~S}$ reduced the effect of PHSML drainage and aggravated structural damage to the kidneys of hemorrhagic-shocked rats.

In an animal model of hemorrhagic shock (17), $\mathrm{H}_{2} \mathrm{~S}$ promoted the systemic inflammatory response syndrome and myeloperoxidase activity in lung tissue. In addition, PPG decreased plasma TNF- $\alpha$, IL-1, IL-6, and IL-10 levels, suggesting that $\mathrm{H}_{2} \mathrm{~S}$ plays an important role in organ injury following hemorrhagic shock. $\mathrm{H}_{2} \mathrm{~S}$ was also involved in inflammatory responses to severe burns in mice and renal ischemia-reperfusion in rats $(18,19)$. We found that PHSML drainage reduced TNF- $\alpha$ levels in shocked rats and that this effect was strengthened by PPG. However, NaHS administration significantly increased TNF- $\alpha$ levels. $\mathrm{H}_{2} \mathrm{~S}$ reduction 
was also related to the mechanism of PHSML drainage for reducing renal injury and the inflammatory response - processes in which $\mathrm{H}_{2} \mathrm{~S}$ plays a negative role.

TLR4 is an important receptor of the innate immune system that recognizes the specific molecular structure of highly conserved binding sites of certain pathogens or their products. TLR4 initiates an inflammatory response through the identification and binding of different pathogen-associated molecular species and is involved in uncontrolled inflammatory responses following hemorrhagic shock $(20,21)$. TLR4 is also involved in lipopolysaccharide-induced kidney injury (22). Our results showed that TLR4, IL-10, and IL-12 levels were significantly increased in the renal tissues of rats in shock, suggesting that TLR4 mediated renal injury after hemorrhagic shock. However, PHSML drainage had no effect on these markers, suggesting that the role of PHSML drainage in alleviating AKI was unrelated to TLR4 or that it resulted from the short observation time in this study. Thus, observation time should be extended in future studies to further clarify the role of TLR4 in AKI induced by PHSML return. Moreover, NaHS, an $\mathrm{H}_{2} \mathrm{~S}$ donor, increased TLR4, IL10 , and IL-12 levels in the renal tissues of rats in the shock + drainage group, but PPG reduced the inflammatory response. Therefore, we can conclude that $\mathrm{H}_{2} \mathrm{~S}$ induces TLR4 to aggravate the renal tissue inflammatory response.

\section{References}

1. Mizock BA. The multiple organ dysfunction syndrome. Dis Mon 2009; 55: 476-526, doi: 10.1016/j.disamonth.2009.04. 002.

2. Wohlauer MV, Sauaia A, Moore EE, Burlew CC, Banerjee A, Johnson J. Acute kidney injury and posttrauma multiple organ failure: the canary in the coal mine. J Trauma Acute Care Surg 2012; 72: 373-378.

3. Rohrig R, Ronn T, Lendemans S, Feldkamp T, de Groot $\mathrm{H}$, Petrat $F$. Adverse effects of resuscitation with lactated ringer compared with ringer solution after severe hemorrhagic shock in rats. Shock 2012; 38: 137-145, doi: 10.1097/SHK.0b013 e31825b4ed9.

4. Wang Y, Yan J, Xi L, Qian Z, Wang Z, Yang L. Protective effect of crocetin on hemorrhagic shock-induced acute renal failure in rats. Shock 2012; 38: 63-67, doi: 10.1097/SHK.0b013 e3182596ec4

5. Deitch EA. Gut lymph and lymphatics: a source of factors leading to organ injury and dysfunction. Ann N Y Acad Sci 2010; 1207 (Suppl 1): E103-E111, doi: 10.1111/j.1749-6632. 2010.05713.x

6. Fanous MY, Phillips AJ, Windsor JA. Mesenteric lymph: the bridge to future management of critical illness. JOP 2007; 8: 374-399.

7. Deitch EA. Gut-origin sepsis: evolution of a concept. Surgeon 2012; 10: 350-356, doi: 10.1016/j.surge.2012.03.003.

8. Niu CY, Li JC, Zhao ZG, Zhang J, Shao XH. Effect of intestinal lymphatic circulation blockage in two-hit rats. World J Gastroenterol 2006; 12: 5805-5812.

9. Zhao ZG, Niu CY, Zhang J, Bo AH. [Effects of mesenteric lymph duct ligation on apoptosis of renal tubule epithelial
Pretreatment with PPG decreased plasma urea levels and $\mathrm{H}_{2} \mathrm{~S}$ levels in the kidneys of hemorrhagic-shocked rats as reported by Mok et al. (13), who evaluated the role of $\mathrm{H}_{2} \mathrm{~S}$ in $\mathrm{AKI}$ following hemorrhagic shock. Our aim, however, was to focus on the relationship between $\mathrm{H}_{2} \mathrm{~S}$ and PHSML drainage, so we did not study the effect of $P P G$ or NaHS on AKI, which is a limitation of this study. The roles of PHSML drainage and PPG on AKI induced by hemorrhagic shock should be compared in future studies.

In summary, PHSML drainage had beneficial effects on $\mathrm{AKI}$ and renal dysfunction following hemorrhagic shock. AKI amelioration was associated with decreased $\mathrm{H}_{2} \mathrm{~S}$ levels and the downregulation of $\mathrm{H}_{2} \mathrm{~S}$-mediated inflammation. These findings provide a sound experimental basis for the clinical prevention and treatment of AKI in critically ill patients with a focus on the lymphatic pathway and $\mathrm{H}_{2} \mathrm{~S}$ regulation.

\section{Acknowledgments}

Research supported by the Key Scientific and Technological Project of Hebei Province (\#11276103D84), and the Foundation of Hundred Innovative Talents in Universities of Hebei Province (\#CPRC047, BR2-105).

cells in rats after two-hits]. Zhongguo Wei Zhong Bing Ji Jiu Yi Xue 2007; 19: 724-726.

10. Niu CY, Zhao ZG, Ye YL, Hou YL, Zhang YP. Mesenteric lymph duct ligation against renal injury in rats after hemorrhagic shock. Ren Fail 2010; 32: 584-591, doi: 10.3109/ 08860221003778031.

11. Ahmad FU, Sattar MA, Rathore HA, Abdullah MH, Tan S, Abdullah NA, et al. Exogenous hydrogen sulfide (H2S) reduces blood pressure and prevents the progression of diabetic nephropathy in spontaneously hypertensive rats. Ren Fail 2012; 34: 203-210.

12. Li L, Rose $P$, Moore PK. Hydrogen sulfide and cell signaling. Annu Rev Pharmacol Toxicol 2011; 51: 169-187, doi: 10.1146/ annurev-pharmtox-010510-100505.

13. Mok YY, Moore PK. Hydrogen sulphide is pro-inflammatory in haemorrhagic shock. Inflamm Res 2008; 57: 512-518, doi: 10.1007/s00011-008-7231-6.

14. Francescato HD, Chierice JR, Marin EC, Cunha FQ, Costa RS, Silva CG, et al. Effect of endogenous hydrogen sulfide inhibition on structural and functional renal disturbances induced by gentamicin. Braz $\mathrm{J}$ Med Biol Res 2012; 45: 244-249, doi: 10.1590/S0100-879X2012007500 016

15. Fan $Y M$, Huang $X L$, Dong $Z F$, Ling $Y L$. [Hydrogen sulfide reduces lipopolysaccharide-induced acute lung injury and inhibits expression of phosphorylated p38 MAPK in rats] Sheng Li Xue Bao 2012; 64: 666-672.

16. Gao C, Xu DQ, Gao CJ, Ding Q, Yao LN, Li ZC, et al. An exogenous hydrogen sulphide donor, NaHS, inhibits the nuclear factor kappaB inhibitor kinase/nuclear factor kappab 
inhibitor/nuclear factor-kappaB signaling pathway and exerts cardioprotective effects in a rat hemorrhagic shock model. Biol Pharm Bull 2012; 35: 1029-1034, doi: 10.1248/ bpb.b110679.

17. Mok YY, Atan MS, Yoke PC, Zhong JW, Bhatia M, Moochhala $S$, et al. Role of hydrogen sulphide in haemorrhagic shock in the rat: protective effect of inhibitors of hydrogen sulphide biosynthesis. $\mathrm{Br} J$ Pharmacol 2004; 143: 881-889, doi: 10.1038/sj.bjp.070 6014.

18. Zhang J, Sio SW, Moochhala S, Bhatia M. Role of hydrogen sulfide in severe burn injury-induced inflammation in mice. Mol Med 2010; 16: 417-424.

19. Hunter JP, Hosgood SA, Patel M, Rose R, Read K, Nicholson ML. Effects of hydrogen sulphide in an experimental model of renal ischaemia-reperfusion injury. Br J Surg 2012; 99: 16651671, doi: $10.1002 /$ bjs. 8956 .
20. Li Y, Xiang M, Yuan Y, Xiao G, Zhang J, Jiang Y, et al Hemorrhagic shock augments lung endothelial cell activation: role of temporal alterations of TLR4 and TLR2. Am J Physiol Regul Integr Comp Physiol 2009; 297: R1670-R1680, doi: 10.1152/ajpregu.00445.2009.

21. Fan J, Li Y, Vodovotz Y, Billiar TR, Wilson MA. Hemorrhagic shock-activated neutrophils augment TLR4 signalinginduced TLR2 upregulation in alveolar macrophages: role in hemorrhage-primed lung inflammation. Am J Physiol Lung Cell Mol Physiol 2006; 290: L738-L746, doi: 10.1152/ ajplung.00280.2005

22. Zhang D, Li Y, Liu Y, Xiang X, Dong Z. Paclitaxel ameliorates lipopolysaccharide-induced kidney injury by binding myeloid differentiation protein-2 to block Toll-like receptor 4-mediated nuclear factor-kappaB activation and cytokine production. J Pharmacol Exp Ther 2013; 345: 69-75, doi: 10.1124/jpet.112. 202481 